\title{
Generation 1.5 Learners: Removing the Mask of Student Invisibility and Recognising the Learning Disconnections That Marred Their Academic Journeys
}

\author{
Elizabeth Serventy and Bill Allen \\ Edith Cowan University, Australia
}

\begin{abstract}
Distinctive cohorts of students revealing inherent problems in managing their learning are on-going concerns in all universities. Students identified as Generation 1.5 learners are an increasing phenomenon in Australian universities yet may be "invisible" or unknown to teaching staff. They are neither fully proficient in their first language nor in English which is typically their second language (L2). Characteristically possessing well-developed basic interpersonal communicative skills, they lack the cognitive academic learning proficiencies essential for tertiary success. This article reports on doctoral research into six Generation 1.5 undergraduates navigating one academic year in one Western Australian university. Key findings include their "invisibility" and how L2 learning "disconnections" marred their studies. Learning disconnections comprise discrepancies and disjunctions driven by the participants' immigration experiences, their academic needs, and their lack of connection with the teaching methods and the university-provided learning support services. Greater awareness of the distinctive features of these learners may improve their academic outcomes.
\end{abstract}

Keywords: Generation 1.5 learners; immigrant students; student invisibility; access; equity; L2 learner profile; learning disconnections.

\section{Introduction}

Rumbaut and Ima (1988) first coined the "Generation 1.5" term to identify a diverse cohort of refugee youth studying English as a second language (L2) in San Diego, California in the United States. The term signified learners neither part of the first generation in an immigrant-receiving country, nor part of the second generation of children born in that country (Rumbaut \& Ima, 1988). North American-based research has highlighted the implications of having increasing numbers of undergraduate university students meeting this L2 learner profile; yet such implications remain under-acknowledged and under-researched (Harklau \& Siegal, 2009; Roessingh \& Douglas, 2012). In relation to the burgeoning and ever-widening range of linguistic capital that exists in students studying in Australian universities, Harper et al. (2011) discuss learner cohorts that fall outside the traditional university student binaries of domestic and international, and English-speaking and non-English speaking backgrounds. Such simplistic divisions, they argue, ignore the diverse complexities of students with different linguistic backgrounds and their developmental needs. Referring to these increasingly complex linguistic profiles, Williamson identifies Generation 1.5 learners and their academic writing approaches as a "significant blindspot" (2012, p. A-9). In noting that "What is known about Generation 1.5 students indicates that their academic trajectories may be different to other LBOTE [language background other than English]", Williamson signals the need to investigate "access, progression and retention" matters (p. 
A-9). This article reports on doctoral research in 2020 that moves understandings of Generation 1.5 students beyond their difficulties coping with L2 academic requirements. While academic difficulties remained a significant, ever-present theme, the research explored the participants' economic, linguistic, personal, political, religious, and social dimensions that impacted, in varying degrees, on their success or otherwise at university. Seeking to increase awareness of what is clearly a unique group of L2 learners, this article focuses on two key findings: the construct of student "invisibility" and the learning "disconnections" that marred their academic journeys. The aim of this article is to raise awareness of, and generate knowledge about, Generation 1.5 learners worldwide as they seek to manage and mediate their academic demands in undergraduate university programs.

\section{An Overview of the Literature}

In an era of environmental change, military conflicts, exclusionary nationalism, political, and religious tensions (Organisation for Economic Co-operation and Development [OECD], 2018), subsequent migration, asylum seeker, and refugee re-settlement programs are now a worldwide phenomenon (International Organization for Migration [IOM], 2020; Phillips \& Simon-Davies, 2017). Major English-speaking, immigrant-receiving countries such as Australia, Canada, New Zealand, the United Kingdom, and the U.S. face associated economic, educational, political, and social repercussions (OECD, 2018). In June 2019, 29.7 percent of Australia's population were born overseas, with increasing numbers of arrivals from the traditionally non-English speaking countries such as China, India, Malaysia, the Philippines, Sri Lanka, and Vietnam (Australian Bureau of Statistics [ABS], 2020). Importantly, in the context of this research, Western Australia (WA) has the highest proportion of overseasborn residents at 35 percent (ABS, 2020).

Since the Generation 1.5 term was introduced (Rumbaut \& Ima, 1988), subsequent and largely North American research focused on language skills and shortcomings. Typically, these learners are not fully proficient in either their first language (L1) or their L2. While often possessing well-developed basic interpersonal communicative skills (BICS), they are generally less skilled in terms of the cognitive academic learning proficiency (CALP) levels essential for academic achievement (Cummins, 2008, 2011; Roessingh \& Douglas, 2012). Additionally, these learners may lack discrete language skills (Cummins, 2008), the rule-governed areas that include grammar, phonology, and spelling. Two crucial academic L2 variables relate to immigrants' age-on-arrival and length of residence in their host countries (Roessingh, 2008). Notably, immigrants arriving between the ages of 12 and 14 enter an L2 educational danger zone in terms of having inadequate time in which to bridge the CALP gap between themselves and their peers for whom English is usually their L1 (Cummins, 2008, 2011; Roessingh \& Douglas, 2012). Other variables include L1 instructional methods, interlanguage considerations (Swan \& Smith, 2010), and formal L2 teaching methods that include the level and duration of instruction and practice (Bereiter \& Scardamalia, 1987; Hinkel, 2020). With differing and diverse L2 lexical and literacy patterns, these learners do not align with the traditional student profile (Harper et al. 2011; Roberge, 2009).

With limited Australian-based research on this learner phenomenon, Ho (2018) describes the deeply-held aspirations and profoundly-felt anxieties of wealthy, middle-class Asian immigrant school students in selective schools in Sydney, Australia. For these, and for immigrant populations of lower socio-economic status, Year 12 is no longer considered the educational finish line for high school graduates (Harklau \& Siegal, 2009). In turn, families subscribe to the rhetoric of tertiary education (TE) being the goal for self-actualised (Maslow, 1943), successful job-seeking individuals. With these considerations in mind, the research reported in this paper addresses the following question: How do participant students who meet the Generation 1.5 learner profile manage their undergraduate studies in a public university in WA over an academic year?

\section{Methodology}

The research used a grounded theory (GT) approach where theory emerges from qualitative data and "theory generation is a consequence of, and partner to systematic data collection and analysis" (Cohen et al., 2011, p. 598). It included a longitudinal dimension to track the same participants over one academic year. With approval from the University's Human Research Ethics Committee, a cross-campus promotion of the research attracted 15 students willing to participate. Having been made aware of the research commitments, only six participants, four females and two males, formally agreed to take part. With home countries comprising Afghanistan, Colombia, Italy, Malaysia, Serbia-Croatia, and South Korea, five of the six participants were aged in their early-twenties and in their first year of study, while the sixth was in their late-thirties and about to begin their second year. Although the small sample size may limit generalisability, theoretical saturation or conceptual rigour (Low, 2019) was 
achieved by generating high quality data and using rigorous analytical processes that collectively delivered substantive theory (Strauss \& Corbin, 1990).

The iterative GT approach of data-generation and analytical processes involved three rounds of semi-structured, in-depth interviewing. However, two participants, citing time constraints, preferred to supply written responses to research questions following their first-round interviews. In line with Strauss and Corbin (1990), the interview transcriptions and written responses were analysed using hierarchical open, axial, and selective coding processes. Codes and emerging major themes were constantly compared and interrogated. Literary, non-technical, and technical literature was accessed throughout the study to inform study findings, memo-writing, and story line development (Leavy, 2017; Strauss \& Corbin, 1990).

\section{Participant Findings}

Findings revealed how these Generation 1.5 participants managed their studies and their lives through the metaphor of an academic highway journey. In navigating their journeys, participants detailed the stuttering progress, the occasional crashes, and the deviations made in meeting university demands and delivering adequate learning performances. In contrast with the participants in Ho's (2018) Sydney-situated study, five participants in this Perth-based study had immigrated from home countries and contexts of adversity; none were from privileged groups, and all had immigrated via the Australian Government's immigration programs. One participant, a self-described "boat-person and queue-jumper", was a refugee who, along with her family, had experienced the perils of dangerous land and sea journeys to eventually reach Australian shores. Crucially, all six participants' post-immigration experiences, while neither ideal nor supportive (Segal, 2002), were significant. Most had faced racism, from macro-aggression to continuous micro-aggressions (Yosso et al., 2009), with discrimination and stigmatisation commonly stated experiences. High school had been the context for many of these adversities, further exacerbated by inadequate academic L2 educational instruction and practice, little recognition of their learning and literacy problems, and few attempts to address them. Occasionally a teacher was mentioned as providing much-needed assistance, but such occurrences were rare, never systematic. While one participant successfully completed all 12 years of their schooling in Australia, another finished high school in their home country. The remaining four participants entered high school on their arrival; one participant left after six months' attendance while three graduated. However, of the four Australian high school graduates, all considered their schooling was unsatisfactory preparation for post-secondary studies and university entrance. Five of the six participants used alternative TE entry pathways, with three choosing university preparation courses. In describing these enabling courses, one participant viewed it as a "complete waste of time", while another judged it as "easy", useful for admission purposes only. Significantly, all six participants subscribed wholeheartedly to the view that university study was the key to their future aspirations in terms of greater employment opportunities and higher standards of living. These views, participants advised, were shared by their parents and L1 community members who regarded a university degree as a passport to future success in their host country. However, these expectations failed to take into account the necessary L2 academic support requirements and time-related considerations implicit in TE. Accordingly, some parents seemed unable to appreciate their children's study demands, instead expecting them to work long hours to supplement family incomes. These influences highlighted crucial cultural dimensions associated with achieving academic success and dealing with disappointment if and when their children experienced failure.

\section{Generation 1.5 Learner Invisibility}

Findings highlighted the importance of the diverse complexities associated with the BICS and CALP dichotomy (Cummins, 2008). Significantly, BICS, their conversational fluency, provided the mask that contributed to their student invisibility, while their CALP-related problems only became apparent after submitting written assignments, typically when well-advanced in their semester studies. As one participant pointed out:

You know, a lot of people don't even know that I'm an immigrant. Like I don't speak like an immigrant ... They just can't get their head around that I'm a European that moved here at the age of 16.

Trying to fit-in rather than stand-out, the participants referred to being fully engaged in class, wanting to be like everyone else in terms of their L2 academic abilities, all the while cognisant they were outsiders rather than insiders (Scott, 2015). As one participant recounted: 
When I am, you know, in a group of Koreans, for example, my mindset changes to, like Korean sort of settings or when I'm in, like with my mates and I will go out for food or drinks, something like that, then my mindset changes...I think my mindset has become very adaptive to certain environmental situations... I see myself as an Australian.

Nevertheless, in attempting to fit-in, another participant described continuing cultural, emotional, and psychological conflicts and pressures still experienced despite having lived in Australia for 17 years: "As a refugee in this country ... Now we're here and we supposedly jumped queues to get here, pushed in line. We've got to work so hard to achieve such great levels of success, and that's when we're accepted." Importantly, fitting-in also included a reluctance by all participants to seek feedback or to question assessment grades. In terms of student-staff interactions and addressing L2 learning difficulties, one advised: "I don't speak out much ... If I struggle but I'm still managing, I will just keep managing." Similarly, another justified their unwillingness to challenge assessment feedback and semester results in this way:

Usually I don't contest the teachers ... Whatever they give me, I'm happy because ... I know it's wrong, but I always think, okay, this person sat down and went through my work, and at some point, they identified that I didn't meet the criteria. And if this person is so knowledgeable, and is my teacher, and is doing the right thing by me says I didn't do it, then probably I didn't do it.

Paradoxically, wanting to fit-in while struggling to manage their L2 academic journeys, contributed to their Generation 1.5 learner invisibility. With these sentiments in mind, discussion now focuses on the second set of findings explored in this article, the range of learning disconnections that signposted their academic journeys.

\section{University Learning Support Disconnections}

The term "disconnection" emerged from the data analysis as a relational concept in the sense of identifying the discrepancies and disjunctions experienced between the participants' L2 academic needs, the teaching methods, and the available, universityprovided support services. Continuum-based, participants' disconnection characteristics were multifaceted, existing between their academic expectations and the realities of TE (Dillon et al., 2007), along with their positionality in terms of cultural, academic, linguistic, and social influences. While the objective was one of self-identity and social transformation (Scott, 2015), pre-and post-immigration drivers underpinned the participants' academic highway journeys. These disconnections included being inadequately prepared to meet essential university academic demands such as reading and writing. In relation to reading requirements, one said: "I feel like I can't stand it for long because it's really, really, really time consuming ... If you have to do pre-reading it goes for three hours." Another described their writing process difficulties: "I feel this thing, how do I start, how do I start?", while a third emphasised their L2 academic writing limitations: "I wish I could just do like verbal essays. That would be so much easier for me. I guess they have to mark my writing." When asked about a current writing assessment task, one participant queried: "What's a narrative?"

Such disconnections were intensified by all participants being unable to access university-provided learning support services in times of greatest need, either online or face-to-face. Findings unequivocally indicated their frustration in being unable to access just-in-time, targeted L2 learning support services. Reflecting the findings of Arkoudis (2019), Arkoudis et al. (2019), and Harvey (2018), all participants considered the current Monday-to-Friday, business hours learning support model outdated and largely inaccessible. One expressed their disappointment: "I know what my constraints are and I'm always willing to do anything to improve it." Another found the university's online support service inadequate: "Like I did it and I completed it but it didn't really change a lot that I do.” As she made clear: “... just not having that one-on-one ... I don't know ... Like even when they write feedback and all this...takes them five days to reply ... and you're like oh just lost interest."

Course scheduling conflicts and time scarcity, rather than a lack of motivation, added to Generation 1.5 learners' invisibility and their learning disconnections. As demonstrated, the term learning disconnections conveys the cumulative impacts of the participants' L2 academic unpreparedness and the university's inadequacies in providing support to them. All participants spoke of wanting real-time, targeted learning support that provided seven-days-a-week flexibility. This disconnection with learning support represented lost opportunities to engage with learning support staff; to become "visible" in terms of their diverse and differing L2 academic needs; and to feel included, valued, and worthy in the academic discourse community (Witkowsky et al., 2016). Lacking many of the crucial cultural capital resources (Yosso, 2005) necessary to successfully manage student-teacher relationships, these learners had limited opportunities to convert academic adversities into achievements. While focused on cultural, work-based organisational learning and development disconnections, Lizier and 
Reich (2020) argue the need for complex adaptive systems' approaches to changing environmental needs by delivering innovative, pragmatic solutions. Similarly, the need for a university-driven response to the diverse academic needs of Generation 1.5 learners was identified in the findings.

\section{Transitioning}

For all but one participant, immigration had provided an escape route that delivered emotional and psychological distance and passage from their adverse home country experiences. All were adamant that university success represented their aspirations for fulfilling economic, educational, personal, and social growth, essentially moving on from pre-immigration adversity to post-immigration advancement while balancing self and familial demands and expectations (Cheng \& McCarthy, 2013; Segal, 2002). As one participant explained: “... when you're in a country where you have the opportunity for education, to advance yourself ... I mean, it was a no-brainer almost."

Most importantly, all participants believed that, in having been accepted and enrolled by the university, they had been judged to have the academic resources necessary to succeed in their studies. Additionally, reflecting the Dunning-Kruger Effect (Dunning, 2011), all participants over-estimated their English language abilities, under-estimated their study time requirements, and were under-resourced in managing their L2 academic journeys. For example, one participant with only six months' high school education, no Australian Tertiary Admission Rank (ATAR), and an unrelated vocational training course qualification, was able to enrol in a psychology degree. Another, the first-in-family to study at university (O'Shea, 2016), described the weight of self, family, and local Hazara community expectations to succeed academically: "My parents came here to give me a chance at a better life through people and knowledge. I can't bear to put their struggles and sacrifices to waste." Despite an inadequate ATAR, by completing a university enabling course, and just passing a supplementary test, she was allowed to enrol in their "dream course" of law. However, they failed all their first-year units. This resulted in their permanently withdrawing from university, experiencing self-identity implications, and dealing with the cultural and social consequences associated with academic failure in one of their community’s "golden professions."

\section{Difficulties in Staying-the-Course}

Adding to ongoing learning disconnections, these Generation 1.5 learners were unfamiliar with the university "game" such as understanding assessment rules, appeals, and redress processes. For two participants, one failed a unit by two points, and another by seven, situations that may have been rectified by earlier engagement with teaching staff and exercising the right to sit a supplementary examination. However, the participants were either unaware, or neither comfortable nor confident in discussing their learning situations earlier in their studies or later in terms of initiating formal assessment processes. Of the three participants who completed their academic year, two still failed units that required repeating in a subsequent semester, at considerable financial cost, as well as complicating future enrolment scheduling. One student's academic unpreparedness undermined their studies from the outset. In failing one unit, and barely passing others, collectively, such academic outcomes will be indicated in the participant's academic transcripts when seeking employment. Even the most successful participant of the group had no ATAR but passed the International English Language Testing System, usually referred to as IELTS, in all areas but writing. Subsequently, sitting a university writing test enabled their admission. Nevertheless, the realities of managing the written demands were evidenced in the lowering of their L2 academic expectations. As this selective overview of the study's findings has demonstrated, being seemingly invisible in the university student community and experiencing disconnections in terms of access and learning support marred their academic journeys (Harvey, 2018).

\section{Discussion}

Education provides the learning capital that immigrants require to successfully compete in increasingly globalised Western economies (Harvey, 2018; Harvey \& Mallman, 2019; OECD, 2018; Roessingh \& Douglas, 2012). However, in terms of the Generation 1.5 learner casualties and survivors in this study, only three were known to have stayed-the-course over the academic year. In dealing with their invisibility and their L2 learning support disconnections, all Generation 1.5 participants were social capital casualties. Typically, these participants lacked the necessary linguistic proficiencies, networks, and resources possessed by students with longer lengths of residence in their host countries (Roessingh, 2008) and by native-born students (Harvey \& Mallman, 2019). Importantly, Yosso (2005) discusses the cultural wealth model developed in relation to U.S. college "Students of Color" (p. 664). Encompassing aspirational, familial, linguistic, navigational, resistance, and social 
capital components, Yosso considers this framework crucial in positioning learning interactions between students and teaching staff. However, all participants in this study were also educational and learning capital casualties of the university's systems and of the cultural, environmental, and social divides that exist between access and success systems (Harvey \& Mallman, 2019; Productivity Commission, 2019). As Harvey (2018) points out, university access without appropriate L2 learning support does not represent educational opportunities for students from non-traditional backgrounds. In addressing Generation 1.5 learner invisibility and learning disconnections, the metaphor of the academic highway journey captured the participants' cognitively-challenging and complex balancing acts in attempting to manage, against-all-odds, their tertiary studies. In explaining why having insufficient resources to counter these snowballing difficulties meant so much to these learners, this discussion is positioned within the psychology of scarcity (Mullainathan \& Shafir, 2013).

\section{The Scarcity Depletion Theory}

Mullainathan and Shafir (2013) describe scarcity as "a subjective sense of having more needs than resources" (p. 86) and discuss its psychology in terms of a pervasive mindset:

When scarcity captures our attention, it changes how we think-whether it is at the level of milliseconds, hours, or days and weeks. By staying top of mind, it affects what we notice, how we weight our choices, how we deliberate, and ultimately what we decide and how we behave. When we function under scarcity, we represent, manage, and deal with problems differently. (p. 12)

Unquestionably, the psychology of scarcity mindset was evidenced in the study findings. All participants acknowledged their L2 limitations yet chose impossible full-time study loads, irrespective of personal and familial responsibilities. However, discussing scarcity invokes the counter-balancing construct of abundance, which in this study was interpreted positively as the participants moved on from their pre-and post-immigration experiences (Roberge, 2009). Abundance was demonstrated negatively in terms of insurmountable L2 academic needs; feeling "cheated", "disconnected", and "excluded" given the lack of accessible and targeted academic L2 learning support; and experiencing the disconnections associated with increasingly online teaching and support services that were at odds with their preferred learning systems and environments.

\section{Implications}

Undoubtedly, disseminating awareness of the Generation 1.5 learner profile as a critical university phenomenon is the first significant implication of the study. However, the fundamental stumbling block for all six study participants was the belief that university admission and course enrolment conferred upon them the L2 academic resources necessary to succeed educationally. In line with this finding, communicating the message that enrolment does not automatically guarantee academic success (Arkoudis, 2019; Harvey \& Mallman, 2019) is paramount. In an ideal Generation 1.5 learner world, a reinventive, whole-of-student-life cycle approach that removes their current invisibility and addresses their range of learning disconnections is crucial (Arkoudis, 2019; Harvey, 2018). This re-inventive approach could include reviewing the assessment processes, rigour, and structures of university preparation courses. These courses should mirror real-time academic tasks, as well as critically assessing and challenging prospective students' capacity for L2 studies. In delivering a cognitivelydemanding and targeted teaching approach, these courses should also demonstrate the realities of transitioning to TE. Consequently, course completion grades and students' subsequent degree enrolment choices require careful ATAR-like considerations in the university's decision-making processes.

In an era of greater access and inclusion in TE, rectifying learning support disconnections is a critical component (Productivity Commission, 2019). It is considered that expanding enrolment data-generation to capture optional but crucial L2 learningrelated information that students might be willing to share includes students' age-on-arrival; length of residence in Australia; and details of the first, second, or perhaps third languages spoken at home. Most importantly, having a default enrolment data field that automatically registers the student as requiring learning support measures unless choosing to opt-out would send a strong message to all students about the importance of using these services. In line with an ideal Generation 1.5 learner world, these services would be targeted and timely in meeting their academic needs. These suggested enrolment processes are in keeping with Mullainathan and Shafir's (2013) scarcity depletion theory and Thaler and Sunstein's (2009) choice architecture concept of nudging. Nudging, a form of decision-making manipulation and marketing, works by making it easier for people to make positive, behavioural choices that are more pragmatic, rational, and self-supportive. Registering L2 academic support needs at enrolment is easier, lessening the cognitive load in decision-making and reducing the perceived stigma students may 
feel in acknowledging their L2 limitations later in their studies (Schwartz, 2004). This opting-in data enrolment strategy would lay the foundations for a whole-of-student-life approach to learning support planning for all students, lessening the transitioning impacts. As Tinto (2017, p. 6) explains:

... another question that universities - and by extension all its members, academics, professional staff, and administration - should ask themselves is: What can they do to lead students to want and have the ability to persist and complete their programs of study within the university? To do so, universities have to see the issue of persistence through the eyes of their students, hear their voices, engage with their students as partners, learn from their experiences and understand how those experiences shape their responses to university policies.

In "misframing" (Scott, 2015, p. 78) and misinterpreting their year-long academic journeys, the Generation 1.5 learner mask of invisibility findings were inextricably linked to a range of interrelated learning disconnections. Collectively, these factors delayed and derailed participants' immigration-influenced, aspirations-focused academic journeys. The promise of transformational and transitional change in re-inventive institutions such as universities (Scott, 2011, 2015) has become part of their "telling-and-selling" stories and marketing strategies. However, while there is an abundance of stories designed to fuel students' high academic aspirations and expectations, there is a scarcity of stories that convey the realities of TE. Accordingly, it is vital to give a higher priority to credible stories that emphasise the need for L2 academic skills (Hinkel, 2020) that can be strengthened by learning support along the way.

\section{Conclusion}

Given the on-going significance of immigration patterns (IOM, 2020), increasing numbers of young people meeting the Generation 1.5 learner profile will begin their TE journeys in Australia (ABS, 2020). In an increasingly uncertain and unstable, globally connected world, universities in major immigration-destination countries such as Australia must urgently address these educational implications (OECD, 2018). The invisibility and learning disconnections discussed in this article were upsetting, unsettling, and unwelcome travelling companions at different junctures of participants' academic journeys. If these learners are to achieve their true academic potential, targeted and just-in-time 'invisibility-free' L2 learning support that is provided in accessible, accommodating, and welcoming teaching environments (Harvey, 2018; Harvey \& Mallman, 2019; Witkowsky et al., 2016) will be critical. The following sentiments validate the value of providing well-structured TE pathways for Generation 1.5 learners:

\footnotetext{
Education doesn't make you happy. Nor does freedom. We don't become happy just because we're free - if we are. Or because we've been educated - if we have. But because education may be the means by which we realize we are happy. It opens our eyes, our ears, tells us where delights are lurking, convinces us that there is only one freedom of any importance whatsoever, that of the mind, and gives us the assurance - the confidence - to walk the path our mind, our educated mind, offers. (Iris Murdoch, n.d.)
}

\section{Acknowledgement}

The research reported on in this paper was conducted as Doctoral research by Dr Elizabeth Serventy at Edith Cowan University, Australia. The completed thesis is entitled: Generation 1.5 learners: Using an arts-informed, grounded theory approach to understanding how these students managed their undergraduate studies in a Perth-based, public university in Western Australia over an academic year. 


\section{References}

Arkoudis, S. (2019, November 4). Shifting the internalisation narrative in higher education [Keynote Presentation]. Edith Cowan University, Joondalup Campus. The ECUlture Conference, Perth, WA, Australia.

Arkoudis, S., Dollinger, M., Balk, C., \& Patience, A. (2019). International students' experience in Australian higher education: Can we do better? Higher Education, 77, 799-813. https://doi.org/10.1007/s10734-018-0302-X

Australian Bureau of Statistics (ABS). (2020). Migration, Australia. (Released 28/04/2020) https://www.abs.gov.au/statistics/people/population/migration-australia/latest-release

Bereiter, C., \& Scardamalia, M. (1987). The psychology of written composition. Lawrence Erlbaum Associates.

Cheng, B. H., \& McCarthy, J. M. (2013). Managing work, family, and school roles: Disengagement strategies can help and hinder. Journal of Occupational Health Psychology, 18(3), 241-251. https://doi.org/10.1037/a0032507

Cohen, L., Manion, L., \& Morrison, K. (2011). Research methods in education $\left(7^{\text {th }}\right.$ ed.). Routledge.

Cummins, J. (2008). BICS and CALP: Empirical and theoretical status of the distinction. In B. Street \& N. H. Hornberger (Eds.), Encyclopedia of language and education (2nd ed., pp. 71-83). Springer Science + Business Media LLC. DOI: $10.1007 / 978-3-319-02321-2 \_6-1$

Cummins, J. (2011). Literacy engagement: Fuelling academic growth for English learners. The Reading Teacher, 65(2), 142-146. https://doi.org/10.1002/TRTR.01022

Dillon, P., Wang, R., \& Tearle, P. (2007). Cultural disconnection in virtual education. Pedagogy, Culture \& Society, 15(2). https://doi.org/10.1080/14681360701403565

Dunning, D. (2011). The Dunning-Kruger effect: On being ignorant of one's own ignorance.

In J. M. Olson \& M. P. Zanna (Eds.), Advances in experimental social psychology. Advances in experimental social psychology, Vol. 44 (p. 247-296). Academic Press. https://doi.org/10.1016/B978-0-12-385522-0.00005-6

Harper, R., Prentice, S., \& Wilson, K. (2011). English language perplexity: Articulating the tensions in the DEEWR "Good Practice principles". International Journal of the First Year in Higher Education, 2(1), 36-48. https://doi.org/10.5204/intjfyhe.v2i1.51

Harklau, L., \& Siegal, M. (2009). Immigrant youth and higher education: An overview. In M. Roberge, M. Siegal \& L. Harklau (Eds.), Generation 1.5 in college composition: Teaching academic writing to U.S.-educated learners of ESL (pp. 25-34). Routledge.

Harvey, A. (2018, November 5). Equity at the end of the student life cycle: Strategies for success, completions and graduate outcomes. [Keynote Presentation]. Edith Cowan University, Joondalup Campus. The ECUlture Conference, Perth, WA, Australia.

Harvey, A., \& Mallman, M. (2019). Beyond cultural capital: Understanding the strengths of new migrants within higher education. Policy Futures in Education,17(5), 657-673. https://doi.org/10.1177\%2F1478210318822180

Hinkel, E. (2020). Teaching academic ESL writing: Practical techniques in vocabulary and grammar. Routledge.

Ho, C. (2018). 'Asians always do well': Getting behind the stereotypes of 'ethnic success' in NSW. Journal of Professional Learning, Semester 1. https://cpl.asn.au/

International Organization for Migration (2020). World migration report 2020. https://www.un.org/sites/un2.un.org/files/wmr_2020.pdf

Leavy, P. (2017). Introduction to arts-based research. In P. Leavy (Ed.). The handbook of arts-based research (pp. 3-21). Guildford Publications.

Lizier, A. L., \& Reich, A. (2020). Learning through work and structured learning and development systems in complex adaptive organisations: Ongoing disconnections. Studies in Continuing Education, 43(2) 261-276. https://doi.org/10.1080/0158037X.2020.1814714

Low, J. (2019)._A pragmatic definition of the concept of theoretical saturation. Sociological Focus, 52(2), $131-139$. https://doi.org/10.1080/00380237.2018.1544514

Maslow, A. H. (1943). A theory of human motivation. Psychological Review, 50(4), 370-396. https://psycnet.apa.org/doi/10.1037/h0054346

Mullainathan, S., \& Shafir, E. (2013). Scarcity: The true cost of not having enough. Penguin Books.

Murdoch, I. (n.d.). Education doesn't make you happy. https://www.quotes.wiki/education-doesnt-make-you-happy-nordoes-free/

Organisation for Economic Co-operation and Development (2018). The resilience of students with an immigrant background: Factors that shape well-being, OECD Reviews of Migrant Education, OECD Publishing. https://www.oecd.org/education/the-resilience-of-students-with-an-immigrant-background-9789264292093-en.htm

O'Shea, S. (2016). First-in-family learners and higher education: Negotiating the 'silences' of university transition and participation. HERDSA Review of Higher Education, 3, 5-23. https://www.herdsa.org.au/herdsa-review-highereducation-vol-3/5-23

Phillips, J., \& Simon-Davies, J. (2017). Migration to Australia: A quick guide to the statistics (Research Paper Series, 201617). Parliament of Australia. 
https://www.aph.gov.au/About_Parliament/Parliamentary_Departments/Parliamentary_Library/pubs/rp/rp1617/Quick_G uides/MigrationStatistics

Productivity Commission (2019). The demand driven university system: A mixed report card. Commission Research Paper. https://www.pc.gov.au/research/completed/university-report-card

Roberge, M. (2009). A teacher's perspective on Generation 1.5. In M. Roberge, M. Siegal \& L. Harklau (Eds.), Generation 1.5 in college composition: Teaching academic writing to U.S. -educated learners of ESL (pp. 3-24). Routledge.

Roessingh, H. (2008). Variability in ESL outcomes: The influence of age on arrival and length of residence on achievement in high school. TESL Canada Journal, 26(1), 87-107. https://doi.org/10.18806/tesl.v26i1.392

Roessingh, H., \& Douglas, S. R. (2012). Educational outcomes of English language learners at university. Canadian Journal of Higher Education, 42(1), 80-97. https://doi.org/10.47678/cjhe.v42i1.182449

Rumbaut, R. G., \& Ima, K. (1988). The adaptation of Southeast Asian refugee youth: A comparative study. Final report to the Office of Resettlement. San Diego, CA: Office of Refugee Resettlement. https://eric.ed.gov/?id=ED299372

Schwartz, B. (2004). The paradox of choice: Why more is less. HarperCollins.

Scott, S. (2011). Total institutions and reinvented identities. Palgrave.

Scott, S. (2015). Negotiating identity: Symbolic interactionist approaches to social identity. Polity Press.

Segal, U. (2002). A Framework for immigration: Applications to Asians in the United States. Columbia University Press.

Serventy, E.J.C. (2020). Generation 1.5 learners: Using an arts-informed, grounded theory approach to understanding how these students managed their undergraduate studies in a Perth-based, public university in Western Australia over an academic year. [Unpublished doctoral thesis]. Edith Cowan University. https://ro.ecu.edu.au/theses/2375/

Strauss, A. L., \& Corbin, J. (1990). Basics of qualitative research: Grounded theory procedures and techniques. Sage Publications.

Swan, M., \& Smith, B. (Eds.). (2010). Learner English: A teacher's guide to interference and other problems (2nd ed.). Cambridge University Press.

Thaler, R. H., \& Sunstein, C. R. (2009). Nudge: Improving decisions about health, wealth and happiness. Penguin Books.

Tinto, V. (1987). Leaving college: Rethinking the causes and cures of student attrition. University of Chicago Press.

Williamson, F. (2012). Generation 1.5: The LBOTE blind spot. Journal of Academic Language \& Learning, 6(2), A1-A13. https://journal.aall.org.au/index.php/jall/index

Witkowsky, P., Mendez, S., Ogunbowo, O., Clayton, G., \& Hernandez, N. (2016).

Nontraditional student perceptions of collegiate inclusion. Journal of Continuing Higher Education, 64, 30-41. https://doi.org/10.1080/07377363.2016.1130581

Yosso, T. J. (2005). Whose culture has capital? A critical race theory discussion of community cultural wealth. Race Ethnicity and Education, 8(1), 69-91. https://doi.org/10.1080/1361332052000341006

Yosso, T. J., Smith, W., Ceja, M., \& Solorzano, D. G. (2009). Critical Race Theory, racial microaggressions, and campus racial climate for Latina/o undergraduates. Harvard Educational Review, 79(4), 659-691. https://doi.org/10.17763/haer.79.4.m6867014157m7071

Please cite this article as:

Serventy, E., \& Allen, B. (2022). Generation 1.5 learners: Removing the mask of student invisibility and recognising the learning disconnections that marred their academic journeys. Student Success, 13(1), 1-9. https://doi.org/10.5204/ssj.1867

This article has been peer reviewed and accepted for publication in Student Success. Please see the Editorial Policies under the 'About' section of the Journal website for further information.

Student Success: A journal exploring the experiences of students in tertiary education.

(c) (i) Except where otherwise noted, content in this journal is licensed under a Creative Commons Attribution 4.0 International Licence. As an open access journal, articles are free to use with proper attribution. ISSN: 2205-0795 